FACTA UNIVERSITATIS

Series: Physical Education and Sport, Vol. 17, No 2, 2019, pp. 221 - 236

https://doi.org/10.22190/FUPES190731022F

Research article

\title{
REGRESSION ALGORITHMS IN ASSESSING THE IMPACT OF MORPHOLOGICAL AND MOTOR CHARACTERISTICS ON THE 60-M SPRINT
}

\author{
UDC 796.422.12.012.1-053.6
}

\author{
Milica Filipović ${ }^{1}$, Veroljub Stanković ${ }^{1}$, \\ Milan Čoh ${ }^{2}$, Biljana Vitošević ${ }^{1}$, Dragana Radosavljevićc \\ ${ }^{1}$ Faculty for Sport and Physical Education, University of Priština, Leposavić, Serbia \\ ${ }^{2}$ Faculty of Sport, University of Ljubljana, Ljubljana, Slovenia \\ ${ }^{3}$ Faculty of Technical Sciences, University in Priština, Kosovska Mitrovica, Serbia
}

\begin{abstract}
The aim of the present study was to identify the relationship between morphological parameters and motor skills that are important for sprint performance in children aged 8 to 16, divided into four age groups (U10, U12, U14, U16), in both genders. The sample consisted of 281 participants who trained sprinting in various athletic clubs. A prediction set of twenty-five variables for assessing morphological characteristics and motor skills was applied, and the criterion variable was the $60 \mathrm{~m}$ sprint. Using a multiple correlation, it has been established that a large number of morphological characteristics have a statistically significant positive correlation with the sprint, especially the longitudinal variables, while the variables of skinfolds showed a low negative statistical significance in relation to the given criterion. In the field of motor skills, the highest number of positive statistically significant correlations were found in the tests of explosive power of the upper and lower extremities, the agility test and horizontal and vertical jump tests. In order to determine which morphological features and motor skills should be applied in sprint running training, we tested related attributes using different algorithms for data mining (LR, MS, $K N N, S V M, M L P, R B F)$. The results suggests that the predictors that we use can continue to be applied with high reliability in assessing sprint performance, but also in the monitoring of the training process in order to profile better sprint achievements.
\end{abstract}

Key words: Youth Athletes, Sprint Running, Morphological Characteristics, Motor Skills, Regression Algorithms

Received July 31, 2019/ Accepted September 16, 2019

Corresponding author: Dragana Radosavljević

Faculty of Technical Sciences, University in Priština, St. Filipa Višnjića bb, 38220 Kosovska Mitrovica, Serbia

Phone: +38128 422340•E-mail: dragana.radosavljevic@ pr.ac.rs 


\section{INTRODUCTION}

It is well known that physical activity is an important determinant of a healthy childhood and adolescence and that today it is not only a predictor of health status, but certainly part of a system for monitoring health. There is general concern about the decrease in physical activity among school children, because it is known that regular physical activity provides the proper growth and development in the field of motor skills, cognition, positive anthropological status and a better body composition, improves aerobic capacity, muscle and bone strength, flexibility, insulin sensitivity, lipid profile, psychosocial status, reduces stress, anxiety, and depression (Smith et al, 2014; Kohl \& Cook, 2013). Therefore, the promotion of quality physical education and adequate physical exercise in the period of growth and development is of fundamental importance, along with a good knowledge of the morphological and physiological aspects of growth and development.

Considering the current situation, it is necessary to increase those types of activities that will contribute to the development of health-related fitness components, i.e., aerobic fitness, muscular fitness, flexibility, and body composition (Cvejić \& Ostojić, 2017)

Each assessment of physical characteristics and abilities in the period of growth and development is closely related to orchestrated physiological developmental changes in the body so that identification of the role of somatic growth in the development of physical characteristics is as important as the role and influence of physical activity on the process of growth and development. The difference in assessment in adults is within the boundaries of genetic inheritance, and in children in the period of growth and development it is a sum of genetic factors, the influence of the external environment, the influence of growth and functional development, and the degree of maturity of biological systems.

Such research is important for assessing motor abilities in children and young people precisely because of the existence of these causal relationships between body dimensions and certain motor skills, and again related to skills specific to certain activities and certain sports disciplines. Understanding these relationships between morphological characteristics and motor skills in assessing the results achieved in more complex and demanding sports disciplines is invaluable because it can indicate both significant correlations as well as sensitive, limiting factors, and therefore can provide a comprehensive insight into physical abilities in the function of development and biological maturation.

It is well established that in ontogenetic development there are "critical" and "sensitive periods" in which a qualitatively new level of possibilities for further development is reached (Viru et al., 1999). Scott (1986) describes the sensitive period as a developmental period in which organizational processes are sensitive to manipulation, leaving aside the importance of the resulting change that represents the critical period. In a pedagogical sense, the sensitive period is defined as the final time in which the child is most sensitive to learning certain skills. Accordingly, it is pointed out that optimal training at the right time during biological maturation can positively increase athletic development due to increased receptivity ("windows of opportunity") (Ford et al., 2012). Thus, although running is considered an innate ability, during the period of growth and development there is improvement in this performance, and the determinants are conditioned by changes in body dimensions. Greater stride length, coupled with the greater applied force (as a result of the increase in muscle mass), is considered crucial in increasing the speed in sprint during the period of growth and development (Rowland, 2005). The development of maximum speed is not constant, but in the period of adolescence there are oscillations, which are related to morphological and motor characteristics, such as increasing 
the length of the step, and reducing the frequency of the step, where these changes are not only the result of morphological changes, but also the result of the disruption of proprio-receptive mechanisms for controlling movement (Čoh, Babić, \& Maćkala, 2010). They also observed that the biggest differences in the development of the maximum speed of pupils of both genders was between 12 and 14, with a greater variation in boys due to the development of strength. They reported that the sensitive period in the development of children aged 9-13 was favorable for the development of speed, mainly due to the development of the central nervous system (CNS) and the formation of a myelin sheath, which is important in transmitting nerve impulses from the CNS to active muscles. Sprint speed is also recognized as a key component of the Youth Physical Development (YPD) program that points to the neural nature of speed training in prepubescence and additional androgenic factors in the adolescence development phase (Lloyd \& Oliver, 2012). The fact that many fitness components are trainable in childhood is particularly important in practical application as a crucial factor for the positive development of young athletes and motivation for participation in sports. Research in sensitive periods of growth and development is always a challenge and provides valuable information on markers that can be used in adequate training processes. In this context, the purpose of our study was to identify the impact of a set of morphological characteristics and motor skills (as a predictor parameter set), relative to the $60 \mathrm{~m}$ sprint (as a criterion parameter set) in young people of different age categories in both genders. To better complete this and to reach those tests that can improve the results of sprint running, different data mining algorithms were used to check the validity of the predictor variables in relation to a given criterion variable.

\section{METHODS}

\section{Sample of participants}

A sample of 281 students divided into 4 age subgroups (U10, U12, U14, U16) of both genders were included in this study. Students trained sprint running in various athletic clubs. The participants and their parents were informed both verbally and by written letter about the nature, methods and objectives of the research, and written permission was obtained prior to participation. The consent of the institutional ethics body for research and experimental work was also obtained. The study was conducted according to the Declaration of Helsinki. During the research, none of the participants reported any kind of health problems.

\section{Measurements}

All measurements were made in accordance with the International Biological Program (IBP). For the assessment of the morphological characteristics the following were monitored: Body height (BH in $\mathrm{cm}$ ), Body mass (BM in $\mathrm{kg}$ ), Leg length (LL in $\mathrm{cm}$ ), Shoulder widthbiacromial range ( $\mathrm{SW}$ in $\mathrm{cm}$ ), Hip width-bitrochanterial range ( $\mathrm{HW}$ in $\mathrm{cm}$ ), Thigh girth (TG in $\mathrm{cm}$ ), Calf girth (CG in $\mathrm{cm}$ ), Knee diameter (KD in $\mathrm{cm}$ ), Ankle joint diameter (AJD in $\mathrm{cm}$ ), Abdomen skinfold (ASF in mm), Thigh skinfold (TSF in mm), Calf skinfold (CSF in mm). Body height was measured with a stadiometer (Seca Z05-PF321, Liverpool,), to the nearest 0,1 $\mathrm{cm}$ and body mass was recorded using a digital scale (Seca 862, Liverpool, England) to the nearest $0,1 \mathrm{~kg}$. The measurements of skinfold thickness were performed on the left side of the body with a skinfold Holtan caliper (Tanner-Whitehouse, UK). 
The assessment of motor skills included the following variables: the Long jump (LJ in $\mathrm{cm}$ ), Triple jump (TJ in $\mathrm{cm}$ )-TJ, Hand tapping in $15 \mathrm{~s}$ (HT in reps), Left foot tapping (FTL in reps), Right foot tapping (FTR in reps), Agility T-test (ATT in s), Vertical jump over five obstacles (VERT-5 in s), Sit-ups in $60 \mathrm{~s}$ (SU60 in reps), Hanging pull-ups (HPU in s), V-sit and reach (VSR in $\mathrm{cm}$ ), Throwing a ball from a standing position (TBST in $\mathrm{m}$ ), Throwing a ball from a seated position (TBSE in $\mathrm{m}$ ), Vertical jump height (VJH in $\mathrm{cm}$ ). In the test used to estimate the speed of movement and explosive strength - a vertical jump over five obstacles, the obstacles of height of $30 \mathrm{~cm}$ were set so that there was a distance of 1 meter between each. The test was performed by measuring the time from the moment when the reflection begins in front of the first obstacle, until the moment the participant hits the last obstacle. The goal is to measure the time needed for the participants to skip all 5 obstacles.

Dynamic variables of vertical jumps (tests used to estimate explosive power of the lower extremities) were determined using a force plate (600x400, type 9286A, Kistler Instrumente AG, Winterthur, Switzerland). The participants performed the test by standing on a Kistler platform to measure the reaction force of the platform, and performed a maximum vertical jump from the half-squat with body preparation. The preparation of the body involved the lowering of the body into the half-squat, with bent knees (knee angle around 90 degrees), hands on hips, and from this position a maximum vertical jump was performed. The participants jumped as high as possible straight up into the air, and landed back on the marked cross. The jump in the opposite direction - the participant assumes a starting upright position, then he performs the opposite movement and jump. The following variables were analyzed: VS - jump height (cm), Pavg50ms / tt - initial acceleration per kilogram body mass (W / kg), Gft - impulse force calculated from flight time (Ns), MP\%-deficit (elastic power index) strength shows the percentage of the height of the SJ jumps in relation to the height of the CMJ jumps (\%).

Criterion variable $-60 \mathrm{~m}$ sprint test - This test involves reaching the maximum sprint speed at 60 meters, wherein the recorded time ends. After the basic warm-up the participant assumes a starting position, one foot in front of the other, with the front leg on the starting line. On the command "ready-set-go", the participant moves from the starting line, with the assistant turning on the stopwatch, which is stopped when the participant passes the target line with his chest.

\section{Statistical analysis}

The relationships between variables were analyzed using the Pearson Correlation Analysis (r), with the level of statistical significance set at $p \leq 0.01$ and $p \leq 0.05$ in SPSS for Windows, version 20.0 (SPSS, Inc., Chicago, IL). In order to realize the problem of research through mathematical algorithms, the WEKA software tool was used in this paper. Weka contains a variety of algorithms in support of methods for data research, of which in this work the following were used: Multiple linear regression - LR, Regression trees - M5, Method to nearest neighbors (k-Nearest Neighbors) - KNN, Support Vector Machine SVM, Neural networks (Multi-Layer Perceptron) - MLP, RBF (Radial Basis Function) neural network - RBF. Models were tested using a 10-fold cross-validation.

\section{RESULTS}

Correlation coefficients (r) of the dependent variable (SPR60) and independent morphological characteristics and motor skills of both genders according to age are shown in 
Table 1. A significant correlation is observed between variables of longitudinal dimensionality with SPR60m, in subgroup U10 equal for both genders, and in subsequent age categories there is a stronger correlation among the boys than the girls. Furthermore, a moderate correlation was observed between the variables of transversal dimensionality and I SPR60, but not in all the age categories. Statistically significant correlations are mainly present in U10 for both genders and in subgroup U14, for the boys. Relationships with skin folds are statistically significant mainly in the U14 and U16 samples ( $\leq \leq 0.05)$, both for the girls and boys. By looking at the correlation analysis of the predictor motor abilities with the criterion variable, it was noted that in all the age categories there is a high positive correlation between SPR60 and tests for the estimation of explosive power of the arm and leg (long jump, triple jump, throwing the ball from the standing position, throwing the ball from the seated position). The strong positive association in all age categories is observed in the agility T-test and jump testing in relation to the criterion variable. In addition, there is a moderate positive correlation between the criterion with the tests for the speed assessment of the upper and lower extremities.

Table 1 Correlation coefficients (r) of the dependent variable (SPR60) and independent morphological characteristics and motor skills for both genders and in all the age groups

\begin{tabular}{|c|c|c|c|c|c|c|c|c|}
\hline & \multicolumn{8}{|c|}{ Pearson Correlation SPR60 } \\
\hline & B10 & G10 & B12 & G12 & B14 & G14 & B16 & G16 \\
\hline $\mathrm{BH}(\mathrm{cm})$ & $-.680^{* *}$ & $-.743^{* *}$ & $-.422^{*}$ & $-.344^{* *}$ & $-.590^{* *}$ & -.286 & $-.755^{* *}$ & -.446 \\
\hline $\mathrm{BM}(\mathrm{kg})$ & $-.610^{* *}$ & $-.489^{* *}$ & -.244 & $-.381^{* *}$ & $-.604^{* *}$ & -.131 & $-.705^{* *}$ & -.254 \\
\hline $\mathrm{LL}(\mathrm{cm})$ & $-.631^{* * *}$ & $-.739^{* *}$ & -.359 & $-.265^{*}$ & $-.491^{* * *}$ & -.131 & $-.679^{* *}$ & $-.518^{*}$ \\
\hline $\mathrm{SW}(\mathrm{cm})$ & $-.473^{* *}$ & $-.431^{* *}$ & -.049 & $-.246^{*}$ & $-.650^{* *}$ & -.156 & -.429 & $-.536^{*}$ \\
\hline $\mathrm{HW}(\mathrm{cm})$ & -0.3 & $-.475^{* *}$ & .068 & -.221 & $-.604^{* * *}$ & -.061 & -.031 & -.392 \\
\hline TG $(\mathrm{cm})$ & $-.399^{*}$ & $-.525^{* *}$ & -.137 & -.201 & $-.477^{* *}$ & -.124 & -.327 & -.017 \\
\hline $\mathrm{CG}(\mathrm{cm})$ & $-.523^{* *}$ & $-.472^{* *}$ & -.269 & $-.253^{*}$ & $-.595^{* *}$ & -.121 & -.432 & -.150 \\
\hline $\mathrm{KD}(\mathrm{cm})$ & -0.3 & $-.569^{* *}$ & -.235 & -.148 & -.274 & -.075 & -.192 & -.393 \\
\hline $\mathrm{AJD}(\mathrm{cm})$ & $-.455^{* *}$ & $-.439^{* *}$ & -.182 & $-.304^{*}$ & -.159 & -.141 & -.284 & -.220 \\
\hline $\mathrm{ASF}(\mathrm{mm})$ & 0.0 & -.002 & $.432^{*}$ & .064 & .235 & .192 & .229 & .129 \\
\hline TSF (mm) & 0.1 & .067 & $.378^{*}$ & .188 & .351 & $.380^{*}$ & $.627^{*}$ & $.500^{*}$ \\
\hline $\mathrm{CSF}(\mathrm{mm})$ & -0.1 & -.045 & .262 & -.080 & .357 & $.433^{* * *}$ & $.551^{*}$ & .237 \\
\hline $\mathrm{LJ}(\mathrm{cm})$ & $.712^{* * *}$ & $.657^{* *}$ & $.850^{* *}$ & $.666^{* *}$ & $.854^{* *}$ & $.460^{* *}$ & $.813^{* *}$ & $.861^{* *}$ \\
\hline $\mathrm{TJ}(\mathrm{cm})$ & $.700^{* *}$ & $.771^{* *}$ & $.785^{\text {** }}$ & $.634^{* *}$ & $.846^{* *}$ & $.522^{* *}$ & $.767^{* *}$ & $.822^{* *}$ \\
\hline HT (reps) & $.551^{* *}$ & $.545^{* *}$ & $.426^{*}$ & $.436^{* *}$ & $.580^{* * *}$ & .181 & .410 & $.624^{* * *}$ \\
\hline FTL (reps) & $.557^{* * *}$ & $.413^{* *}$ & .358 & $.393^{* *}$ & $.534^{* *}$ & .265 & .083 & .295 \\
\hline FTR (reps) & $.622^{* *}$ & $.402^{* *}$ & $.421^{*}$ & $.269^{*}$ & $.546^{* *}$ & $.498^{* * *}$ & .335 & $.526^{*}$ \\
\hline ATT (s) & $-.862^{* * *}$ & $-.696^{* *}$ & $-.826^{* *}$ & $-.492^{* *}$ & $-.717^{* *}$ & $-.505^{* *}$ & $-.555^{*}$ & $-.689^{* *}$ \\
\hline VERT-5 (s) & $-.529^{* *}$ & $-.367^{*}$ & -.323 & -.160 & $-.743^{* *}$ & -.162 & -.106 & $-.473^{*}$ \\
\hline SU60 (reps) & $.653^{* * *}$ & $.385^{*}$ & $.621^{* *}$ & $.597^{* *}$ & $.443^{*}$ & $.345^{*}$ & -.099 & .181 \\
\hline HPU (s) & $.344^{*}$ & .299 & $.517^{* *}$ & .032 & .081 & .132 & -.026 & .375 \\
\hline $\operatorname{VSR}(\mathrm{cm})$ & .180 & .126 & .290 & .185 & .076 & .151 & .388 & -.163 \\
\hline TBST (m) & $.739^{* *}$ & $.694^{* *}$ & $.719^{* *}$ & $.651^{* *}$ & $.736^{* *}$ & $.327^{*}$ & $.812^{* *}$ & $.706^{* *}$ \\
\hline TBSE (m) & $.789^{* * *}$ & $.720^{* * *}$ & $.574^{* *}$ & $.418^{* * *}$ & $.779^{* * *}$ & $.337^{*}$ & $.714^{* *}$ & $.781^{* * *}$ \\
\hline $\mathrm{VJH}(\mathrm{cm})$ & $.666^{* * *}$ & $.572^{* *}$ & $.706^{* *}$ & $.574^{* * *}$ & $.595^{* *}$ & $.365^{*}$ & .474 & $.838^{* *}$ \\
\hline
\end{tabular}




\section{Concept of Regression}

The idea of regression is to try using the input variables mapping output in the form of a continuous expected resulting function. The regression models use: unknown parameters $(\beta)$, independent variables $(X)$, and dependent variables $(Y)$. The regression model connects $Y$ with $X$ and $\beta$.

$$
Y \approx f(X, \beta)
$$

$L R$

The multiple linear regression is a popular technique that defines a mathematical model that uses multiple independent variables to predict the outcome of a variable that is predictable (dependent variable). The multiple linear regression model in general terms can be defined as:

$$
y_{i}=\beta_{0}+\beta_{1} x_{i 1}+\beta_{2} x_{i 2}+\cdots+\beta_{p} x_{i p}+\varepsilon
$$

where the term $i=n$ represents observation, $y_{i}$ - the dependent variable, $x_{i}$ - independent (explanatory) variable, $\beta_{0}$ - y-intercept (const), $\beta_{i}$ - coefficient of inclination for each explanatory variable, $\varepsilon$ - model deviations (residual).

M5P

M5 is an algorithm that combines a classic decision tree with a linear regression function in the nodes. The algorithm for the induction of the decision tree is used to form a tree, but instead of an entropy, for each inner node as the division criterion, minimization of variance in each of the subtrees is used.

\section{K-Nearest Neighbors Algorithm (kNN - k-nearest neighbors)}

K-nearest neighbors algorithm is one of the simplest machine learning algorithms. It represents an instance-based learning algorithm. It is used for classification and regression. The input of the algorithm consists of the $k$ closest training examples learned, and the output represents the value of the object. The value is obtained as the average value of the $k$ nearest neighbors.

SVM

SVM (Support Vector Machine) is used to implement a SMOReg (algorithm recovery vector method). By using the corresponding nonlinear function, the input data is mapped to a multi-dimensional space in which a linear regression is formed (Shevade, Keerthi \& Bhattacharyya, 1999). 


\section{MLP Regressor}

Multilayer perceptrons represent the most prominent type of artificial neural networks. They belong to the class of networks with feeding in advance (feedforward network), which do not contain any cycles. A backpropagation algorithm is implemented to build a neural network model. Neural networks do not approximate one function that connects the inputs to the output, but the output (activation) functions are used in several layers, thus achieving non-linearity. The BFGS (Broyden-Fletcher-Goldfarb-Shanno) algorithm is a method for solving unconstrained nonlinear optimization problems which trains a multilayer perceptron by minimizing the given loss function plus a quadratic penalty. The identity function is activated in the output layer.

\section{$R B F$}

The RBF (Radial Basis Function) Regressor implements RBF Networks by training in a supervised manner by minimizing squared error with the BFGS (Broyden-FletcherGoldfarb-Shanno algorithm) method. The ridge parameter is used to penalize the size of the weights in the output layer, which implements a simple linear combination.

Collection of data

Table 2 Morphological characteristics of the participants

\begin{tabular}{|c|c|c|c|c|c|c|c|c|c|c|c|c|c|c|}
\hline Partic & Age & BH & BM & LL & SW & HW & TC & $\mathrm{CC}$ & KD & TD & ASF & TSF & CSF & SPR60 \\
\hline Min & 10 & 125.70 & 24.20 & .60 & 24.30 & 17.00 & 30.40 & 23.50 & 6.00 & 5.30 & .28 & 0.62 & 0.34 & 7.54 \\
\hline Max & 16 & 191.00 & 70.70 & 99.90 & 40.20 & 29.00 & 91.90 & 39.50 & 10.00 & 8.10 & 6.60 & 4.30 & 9.92 & 11.61 \\
\hline Std. Dev. & 1.79 & 10.83 & 9.91 & 6.25 & 3.08 & 2.54 & 5.97 & 3.17 & 0.63 & 0.46 & 0.79 & 0.66 & 0.98 & 0.81 \\
\hline
\end{tabular}

The figure presents the results of the measured and numerically assessed values of the SPR60 parameter for the M5 algorithm where it is also possible to visualize a good match between the estimated and measured data for the values of the SPR60 parameter $(\mathrm{spr} 60=$ $0.3066 *$ Age $=12.10+0.1949 *$ Age $=10-0.0372 * \mathrm{p} 2-0.0416 * \mathrm{p} 7+0.0797 * \mathrm{p} 10+0.4686 * \mathrm{p} 11+11.2758)$.

For more than $50 \%$ of the participants in the calculation of SPR60 the error was less than $3.5 \%$, and for more than $90 \%$ of the participants, the error was less than $8 \%$.

The relatively small differences and small relative errors that can be perceived for a large number of samples indicate that the numerically calculated values give satisfactory matching with the measured values. This is indicated by small average values of absolute values of the difference (0.365), as well as relative errors $(3.85 \%)$.

Figure 1 shows the comparisons between true and estimated values in U10, U12, U14 and $\mathrm{U} 16$ for both genders. The $y$ axis represents the true and estimated values for the followed criteria and the $x$ axis represents the participants. The white boxes represent the M5 algorithm prediction and the black squares represent the true value. 


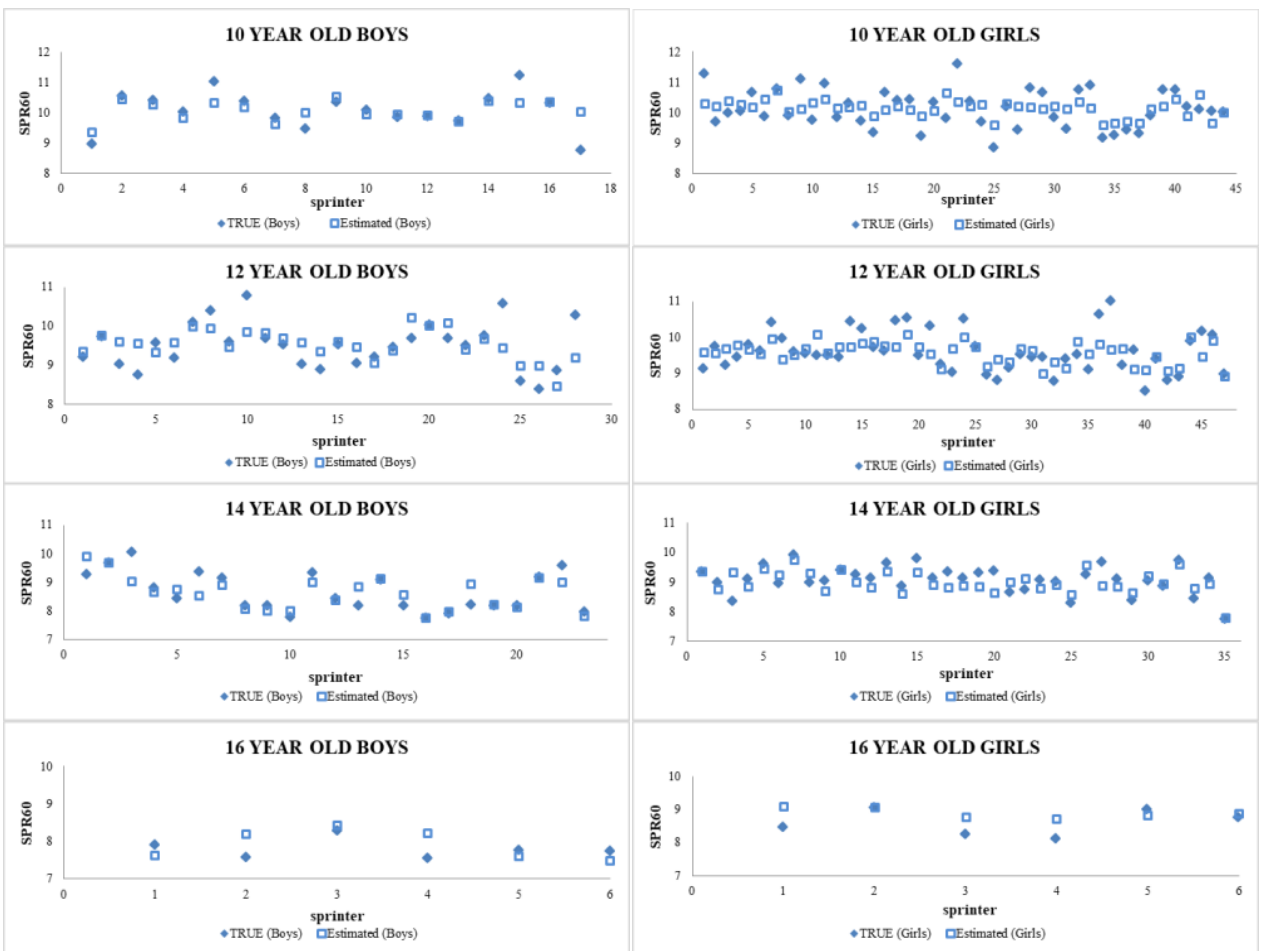

Fig. 1 Model estimation for the $60 \mathrm{~m}$ sprint for boys and girls U10, U12, U14, U16

\section{Performance evaluation}

The performance of the predictor is calculated by comparing the estimated value with the actual value. There are various methods for evaluation such as: CC - Correlation coefficient, Mean Absolute Error (MAE), Root Mean Squared Error (RMSE), and Relative Absolute Error (RAE).

Table 3 The results of regression algorithms for morphological characteristics

\begin{tabular}{lllll}
\hline Algorithm & CC & MAE & RMSE & RAE (\%) \\
\hline LR & 0.786 & 0.399 & 0.504 & 61.95 \\
M5 & 0.789 & 0.392 & 0.501 & 60.80 \\
KNN & 0.741 & 0.428 & 0.547 & 66.44 \\
SVM & 0.783 & 0.400 & 0.508 & 62.09 \\
MLP & 0.739 & 0.440 & 0.561 & 68.27 \\
RBF & 0.789 & 0.400 & 0.499 & 62.20 \\
\hline
\end{tabular}

Legend: MAE - Mean absolute error, CC - Correlation coefficient, RMSE - Root mean square error, RAE-Relative absolute errors, LR- Multiple linear regression, M5 - Regression trees, KNN - Method of k nearest neighbors, SVM - Support vector method, MLP - Neural networks, RBF - Neural network

$\mathrm{K}$ nearest neighbors algorithm gives the optimal result for the 7 nearest neighbor-cases $(\mathrm{k}=7)$. 
A good result is attributes that have a high correlation with the output variable, and are not correlated with each other. High attribute correlation values with the output parameter (in all algorithm s>0.7) indicate that they can be used to numerically evaluate the value of the SPR60 parameter. The RMSE values for the tested algorithms are shown in the table. The test results show that all the models are usable (RMSE <0.55) and give approximately the same results.

Table 4 Results of the regression algorithms for motor skills

\begin{tabular}{lcccc}
\hline Algorithm & CC & MAE & RMSE & RAE (\%) \\
\hline LR & 0.894 & 0.290 & 0.365 & 45.09 \\
M5 & 0.894 & 0.288 & 0.365 & 44.65 \\
KNN & 0.841 & 0.339 & 0.439 & 52.59 \\
SVM & 0.894 & 0.285 & 0.364 & 44.32 \\
MLP & 0.853 & 0.339 & 0.430 & 52.67 \\
RBF & 0.893 & 0.289 & 0.365 & 44.88 \\
\hline
\end{tabular}

Legend: MAE - Mean absolute error, CC - Correlation coefficient, RMSE - Root mean square error, RAE -Relative absolute errors, LR - Multiple linear regression, M5- Regression trees, KNN - Method of

$\mathrm{k}$ nearest neighbors, SVM - Support vector method, MLP - Neural networks, RBF - Neural network

The $\mathrm{K}$ nearest neighbors algorithm gives the optimum result for 4-nearest neighbors of the case $(\mathrm{k}=4)$. Looking at the absolute error (MAE), the best result is provided by the support vector algorithm. With the support vector, the mean absolute error is 0.285 , which can be interpreted as a deviation from the real SPR60 value. However, other algorithms give a result in the form of a similar error value. Multiple linear regression algorithms, regression trees, and RBF neural networks give an error of less than 0.3 , while algorithms to nearest neighbors and artificial neural networks have an error of less than 0.34 .

A good result is attributes that have a high correlation with the output variable, and are not correlated with each other. The high values of the attribute correlation with the output parameter (in all algorithms > 0.84) indicate that they can be used for the numerical estimation of the verification of the SPR60 parameter. The best results are given by multiple linear regression algorithms, regression trees, support vector algorithms, and RBF neural networks.

The test results show that all models are usable because the RMSE values are relatively small (RMSE $\leq 0.365)$.

Table 5 Results of the regression algorithms for morphological characteristics and motor skills (total)

\begin{tabular}{lcccc}
\hline Algorithm & CC & MAE & RMSE & RAE (\%) \\
\hline LR & 0.888 & 0.293 & 0.377 & 45.46 \\
M5 & 0.886 & 0.293 & 0.378 & 45.49 \\
KNN & 0.836 & 0.357 & 0.446 & 55.38 \\
SVM & 0.899 & 0.292 & 0.371 & 45.41 \\
MLP & 0.869 & 0.319 & 0.411 & 49.65 \\
RBF & 0.891 & 0.287 & 0.369 & 44.59 \\
\hline
\end{tabular}

Legend: MAE - Mean absolute error, CC - Correlation coefficient, RMSE - Root mean square error, RAE -Relative absolute errors, LR - Multiple linear regression, M5- Regression trees, KNN - Method of k nearest neighbors, SVM - Support vector method, MLP - Neural networks, RBF- Neural network 
The $\mathrm{K}$ nearest neighbors algorithm gives the optimal result for the 6 nearest sample neighbors $(\mathrm{k}=4)$.

To predict the Sprint attribute at 60 meters, the results are shown in the following table. Looking at the mean absolute error, the best result is provided by the RBF neural network algorithm. MAE for the RBF neural network algorithm is 0.287 , but very similar results are obtained for other observed algorithms. The root mean square error RMSE cannot easily be interpreted as an absolute error, but is still significant. The RBF neural network algorithm gives a slightly better result than the other studied algorithms. The root mean square error in the RBF neural network algorithm is 0.369 and for the multiple linear regression algorithm is 0.377 .

\section{DISCUSSION}

In order to understand the possible mechanisms underlying the sprint performance, we have explored the training process of boys and girls classified into 4 age subgroups (U10, U12, U14 and U16) and investigated the existence of certain morphological characteristics and motor skills that are important for better sprinting performance. By obtaining insight into the correlation analysis, we can categorize the results into the influence of morphological characteristics and the influence of different groups of motor tests: tests of explosive power of the upper extremities and lower extremities, agility tests, tests for the assessment of repetitive strength, and jump testing, both horizontal and vertical. What is specific to the population of the participants is the fact that different age groups of both genders from pre-puberty to adolescence are followed.

Initially, in the morphological characteristics, a significant correlation is observed in body height, mass and length of the leg compared to the criterion variable SPR60 in the age group U10 and U14. Taking these variables in relation to gender, a significant correlation in both genders is evident in the age group U10, with a smaller number of significant correlations in the age group U12, in favor of the girls, whereas in the age U14 and U16 a larger number of significant correlation is present among the boys. Significant correlates are accompanied by rapid growth and development, as in this period a small difference in biological maturation may imply an apparent difference in body height and mass, which subsequently affects a huge difference in sprint performance (Gil, Ruiz, Irazusta, Gil, \& Irazusta, 2007).

Body height is related to the length of the legs, which together cause a greater stride length that with frequency represents the most important factor in determining sprint performance (Papaiakovou et al., 2009). Adding body mass as a factor of acceleration and strength, it is clear that these factors are important determinants of speed in the sprint, and this is in agreement with other studies (Wong, Chamari, Dellal, \& Wisløff, 2009; Mujika, Spencer, Santisteban, Goiriena, \& Bishop, 2009; Malina et al., 2005). The skinfolds did not prove to be a significant sprint performance factor, except for the U14 group in the case of the girls and U16 groups, for both boys and girls, as a negative predictor representing a ballast mass and decreasing relative strength (Babić, 2005).

Observing the correlation coefficient of motor skills compared to SPR60, the largest number of positive statistically significant values was recorded in the age group U10 equally for both boys and girls, in the U12 group slightly more among the girls, while in the U14 the boys had the advantage, and the smallest number of significant correlations was present in 
U16. Significant correlation associated with the sprint was observed in the tests of explosive power of the upper and lower extremities (HT, TBST, TBSE, FTL, FTR), agility T-test, and jumps as tests of explosive strength (LJ, TJ, VERT-5, VJH), while tests for repetitive strength and flexibility (HPU and VSR) as basic motor tests did not prove significant in correlation with our criterion - SPR60. Tests of the explosive power of the lower and upper extremities indicate a well-known interweaving effect of their combined strength, because the arms generate the rhythm of the legs and maintain the balance and stability of the body, which contributes to the speed of movement. When observing agility, it is known that it represents a complex manifestation of motor abilities that is narrowly determined by the biomechanical background and morphological characteristics, but often the technical nature of its outcome is emphasized. It is believed that the agility capacity is defined as early as age 14 by the development of the nervous and muscular system, the development of coordination, and by the influence of sex hormones. However, often by training strength, speed, coordination and flexibility, agility can be further developed. A body of literature indicates that there are contradictory results on the relationship between agility and sprinting. Recently, Bidaurrazaga-Letona et al. (2015) in a population of young players aged 10-14 over a studied period of ten months analyzed the relationship of maturation, age, body size, the vertical jump and sprint, and concluded that the agility test is a reliable and objective instrument in assessing adolescent athletes. In the research of Negra et al. (2017), a high statistically significant association between agility and sprint was obtained at $10 \mathrm{~m}$ and $20 \mathrm{~m}$ in a group of young soccer players aged 12, and Mathisen \& Pettersen (2015) also reported a significant correlation between agility and sprint at $20 \mathrm{~m}$ among young soccer players aged 13-14. However, there are constraints in the results, as the research is not often uniform, nor are the tests, which frequently mislead researchers and point to the complexity and specificity of agility. For example, the results that frequent changes in direction affect the reduction of velocity (Gambetta, 1990) or that speed has limited benefit in improving the agility of rugby players (Corvo, 1997), and that the agility training is superior to speed improvement, but that speed training does not improve significantly the 50m sprint (Hilsendager, Strow, \& Ackerman, 1969). Young, Hawken, \& MCdonald, (1996), as well as Buttifant, Graham, \& Cross, (1999), did not find significant correlations between the sprint and the agility test in Australian soccer players. Little \& Williams (2005), exploring this problem in the population of professional players, conclude that acceleration, maximum speed and agility are relatively independent attributes. This is confirmed by the study of Young, McDowell, \& Scarlett (2001), who examined the specificity of the response to sprint and agility training over 6 weeks, with straight sprint training at 20$40 \mathrm{~m}$ significantly improved the sprint performance at $30 \mathrm{~m}$, but the improvement in performance decreased as the agility requirements in number and intensity of directional changes increased. Agility training has resulted in significant enhancements in the change-ofdirection test, but there has been no significant improvement in sprint performance. These authors point out the specificity of the training and indicate that training in speed and agility produces different specific performance gains, which differ physiologically and biomechanically. Our results, however, indicate that agility is a key predictor of optimum performance, and that the T-test, as an agility assessment, can objectively be implemented in the assessment of sprint achievements. They could, therefore, be read in both directions, in both genders, in the sense that the T-test of agility in both boys and girls positively statistically influenced the improvement of the dependent variable SPR60, and vice versa, that running training influenced the better performance on this agility test. 
Correlation in the tests of explosive leg strength and power in vertical and horizontal reflections (LJ, TJ, Vert-5, VJH) compared to the criterion variable showed a high positive statistical significance and confirmed the essential importance of these predictors on the performance of the sprint. Our results are consistent with the research of other authors, so Comfort, Stewart, Bloom, \& Clarkson (2014) in a young soccer population showed a strong correlation between SJ (squat jumps) height and CMJ (countermovement jumps) height with $5 \mathrm{~m}$ and $20 \mathrm{~m}$ sprint times. Marián, Katarína, Dávid, Matúš, \& Simon (2016) reported that 8 weeks of jump squat training of male students led to significant improvements in $50 \mathrm{~m}$ sprint time, while Williams, Oliver \& Faulkner (2011), assessing the progress of young soccer players aged 12-16, found that there are changes in performance $(10 \mathrm{~m}, 30 \mathrm{~m}$ and vertical jump) on an annual basis (10 m sprint time was improved at a rate of $3.1 \%$ per year, $30 \mathrm{~m}$ sprint time by a rate of $2.7 \%$ per year, and jump height by a rate of $6.9 \%$ per year) pointing to the association between greater maturity and physical development and athletic performance. A vertical jump over five obstacles (VS5P) belongs to the complex coordinated athletic disciplines where the speed of movement and explosive power are the main determinants. The fact that this parameter is in a high positive statistically significant correlation relative to the dependent variable among the boys in U14 but also the girls in u16 clearly indicates that this moment of biological maturation has contributed to being able to deal with much more complex tasks that require higher intensity, and neuromuscular coordination requirements, than before.

A major advantage of using neural networks as well as other algorithms for data mining is the ability to solve complex problems where there is a connection between input and output, which sometimes due to the complexity of the relationship cannot be solved by standard statistical methods. These algorithms and neural networks are then used to identify the real nature of these relationships, but mainly to solve modeling and prediction problems (Haykin, 1994; Maszczyk, Roczniok, Waśkiewicz, Czuba, \& Mikołajec, 2012). Considering that most relationships in sports science are not linear and that any change in variable on one axis will consequently affect the variable in the second axis, researchers are turning to neural models and algorithms as a new potential for predicting results (Maszczyk, et al., 2014). In the present study, using different types of algorithms, we tested whether we made a good choice of predictor variables for evaluating a criterion variable, and we obtained high correlation values of the attribute with the output dependent variable in all algorithms, where the coefficient of correlation is CC > 0.7 (Table 3.), indicating that they can further be used with high reliability for assessing the given criterion variable SPR60. Using the morphological characteristics in mathematical regression algorithms to estimate the SPR60 parameter, the high validity of these proposed predictor variables for the criterion variable estimation (MAE <0.44; RMSE <0.561) was confirmed (Table 3). In determining the percentage of the relative error with respect to SPR60m, the resulting error is less than $3.5 \%$, which means that the estimated variables can be used in further research with a precision of approximately $96 \%$ (Fig. 14). The analysis of motor skills using regression algorithms also confirmed the high validity of the proposed predictor variables for estimating the criterion variable (whereby for all mathematical algorithms used in this paper, MAE $<0.339$ and RMSE $<0.439$ ) (Table 4), indicating that the used motor skills are highly valid attributes for evaluating SPR60. Taking together both morphological characteristics and motor skills to evaluate the dependent variable using different algorithms, even better results are obtained (MAE <0.357; RMSE <0.446) (Table 5), further indicating the high validity of any proposed 
predictor variables for the evaluation of the criterion SPR60. Based on all the above indicators, it can be concluded that the proposed mathematical regression algorithms can successfully be used to numerically estimate the values of the SPR60 parameter either by using only morphological parameters or only motor abilities, or both together.

Similar results were obtained by the test sample method, where two thirds of the sample were used for learning algorithms, and one third for validation of the results, so this type of validation test showed that all the proposed algorithms can be used for a numerical estimation of SPR60m values (CC> 0.8) (Table 4). By analyzing the 10-fold cross-validation of motor skills using regression algorithms, the high validity of the proposed predictor variables for evaluating the criterion variable was confirmed, with an error of less than 0.34 , indicating that these motor abilities are highly valid attributes for estimating the SPR60m. When evaluating the common variables of the participants relative to the dependent variable using different algorithms, the values of the correlation coefficient CC> 0.7 were also obtained, and particularly interesting results were obtained by using neural networks and support vector machines - SVM that failed to outperform the RBF algorithm neural network, and also linear regression, which is one of the simplest algorithms for the regression problem, and all together suggests that the assessment analysis of the Sprint attribute at 60 meters is indeed a challenging task.

The use of these algorithms today represents a significant approach in determining complex problems and the invention of highly realistic models in the field of sport, so it is used to estimate predictions of outcomes, such as talent identification, evaluating the strategy of the game, predicting load in training, predicting the frequency of injuries in sports, predicting performance in both individual and team sports (McCullagh \& Whitfort, 2013; Silva et al, 2007; Dutt-Mazumder, Button, Robins, \& Bartlett, 2011; Fister, Fister, \& Fister, 2019). Recently, the application of these algorithms has become an integral part of many sports training strategies in order to improve technical-tactical tasks on the one hand, and also psycho-physical performance, following the training session tactics, evaluating, optimizing and advancing athletes through quick interactive feedback answers. Their implementation goes one step further, and the obtained data are used for, for example, optimizing the position of players in team sports, for detecting doping in sports, for generating a good training process in accordance with the personal abilities of an athlete, monitoring their physiological parameters, nutrition, dosing intensity of training in order to prevent overtraining, but also for many other purposes, such as the analysis of opponents and the detection of their weaknesses (Fister, Ljubić, Nagaratnam-Suganthan, \& Perc, 2015). The future directions of research in this field will definitely further determine the possibilities of added applications of these algorithms as an attractive model for solving complex issue responsible for the potential of sports performance.

\section{CONCLUSION}

The main goal of this study was to examine the influence of certain morphological characteristics and a combination of basic and specific motor skills that are important for sprint performance in children aged 10 to 16 , of both genders. The results suggest that a large number of morphological characteristics are in a statistically significant positive correlation with sprint performance, in the U10 equally among boys and girls, in U12 a 
slightly higher positive correlation for the girls, and in U14 and U16 for the boys, which is consistent with the manner of biological maturation and development. Analyzing motor skills, the highest number of positive statistically significant correlations were recorded in the tests of explosive power of the upper and lower extremities, the agility test, and the tests of horizontal and vertical jumps. Using different types of mathematical algorithms for data mining ((LR, M5, KNN, SVM, MLP, RBF), we tested our chosen set of predictor variables for evaluating the criterion variable and we obtained all the algorithms in high value attribute correlation with output dependent variable, where the coefficient of correlation is CC>0.7, indicating that they can continue to be used with high reliability to estimate our specific SPR60 criterion variable. The application of these algorithms in the monitoring of the training process can enable the creation of highly reasonable prediction models of sports performance achievement by using previously selected competent variables.

The practical, applicative value of the obtained results is based on the premise that with the training of carefully selected exercises, adequate programming and optimum load, a significant level of morphological characteristics and motor skills that are indicative for sprint performance can be achieved, especially in children and adolescents in the plastic growth and development period.

\section{REFERENCES}

Babić V. (2005). Utjecaj motoričkih sposobnosti i morfoloških obilježja na sprintersko trčanje (Influence of motor skills and morphological characteristics on sprinting). Doctoral Dissertation, Zagreb: University of Zagreb, Faculty of Kinesiology. In Croatian

Bidaurrazaga-Letona, I., Carvalho, H.M., Lekue, J.A., Badiola, A., Figueiredo, A.J., \& Susana María, G. (2015). Applicability of an agility test in young players in the soccer field. Revista Brasileira de Medicina do Esporte, 21(2), 133-138.

Buttifant, D., Graham, K, \& Cross, K. (1999). Agility and speed of soccer players are two different performance parameters. Journal of Sports Sciences, 17, 809.

Comfort, P, Stewart, A, Bloom, L, \& Clarkson, B. (2014). Relationships between strength, sprint, and jump performance in well-trained youth soccer players. Journal of Strength and Conditioning Research, 28(1), 173-177.

Corvo, A. (1997). Agility. Rugby League Coaching Magazine, 1, 1-2.

Cvejić, D., \& Ostojić, S. (2018). Effects of the FITT program on physical activity and health-related fitness in primary school age children. Facta Universitatis series Physical Education and Sport, 15(3), 437-451.

Čoh, M., Babić, V., \& Maćkala, K. (2010). Biomechanical, neuro-muscular and methodical aspects of running speed development. Journal of Human Kinetics, 26, 73-81.

Dutt-Mazumder, A., Button, C., Robins, A., \& Bartlett, R. (2011). Neural network modelling and dynamical system theory. Sports Medicine, 41(12), 1003-1017.

Fister, I., Fister, Jr. I., \& Fister, D. (2019). BatMiner for identifying the characteristics of athletes in training. In: Computational Intelligence in Sports. Adaptation, Learning, and Optimization, vol 22. Springer, Cham.

Fister, I., Ljubić, K., Nagaratnam Suganthan, P., \& Perc, M. (2015). Computational intelligence in sports: Challenges and opportunities within a new research domain. Applied Mathematics and Computation, 262, 178-186.

Ford, P., Collins, D., Bailey, R., MacNamara, A., Pearce, G., Toms, M. (2012). Participant development in sport and physical activity: The impact of biological maturation. European Journal of Sport Science, 12(6), 515-526.

Frank, E. (2019). Weka 3: Machine Learning Software in Java. Retrieved June 3, 2019 from http://weka.sourceforge. net/doc.packages/multiLayerPerceptrons/weka/classifiers/functions/MLPRegressor.html.

Gambetta, V. (1990). Speed development for football. Strength \& Conditioning Journal, 12(1), 45-46.

Gil, S., Ruiz, F., Irazusta, A., Gil, J., \& Irazusta, J. (2007). Selection of young soccer players in terms of anthropometric and physiological factors. Journal of Sports Medicine and Physical Fitness, 47, 25-32. 
Haykin, S. (1994). Neural networks, a comprehensive foundation. New York: Macmillan College Publishing Company.

Hilsendager, D.R., Strow, M. H., \& Ackerman, K.J. (1969). Comparison of speed, strength, and agility exercises in the development of agility. Research Quarterly. American Association for Health, Physical Education and Recreation, 40(1), 71-75.

Kohl, H.W., \& Cook, H.D. (2013). Educating the student body: Taking physical activity and physical education to school. Washington: National Academies Press. doi:https://doi.org/10.17226/18314

Little, T., \& Williams, A.G. (2005). Specificity of acceleration, maximum speed, and agility in professional soccer players. Journal of Strength and Conditioning Research, 19 (1), 76-78.

Lloyd, R.S., \& Oliver, J.L. (2012). The youth physical development model: A new approach to long-term athletic development. Strength \& Conditioning Journal, 34, 61-72.

Malina, R.M., Cumming, S.P., Kontos, A.P., Eisenmann, J.C., Ribeiro, B., \& Aroso, J. (2005). Maturityassociated variation in sport-specific skills of youth soccer players aged 13-15 years. Journal of Sports Sciences, 23, 515- 522.

Marián, V., Katarína, L., Dávid, O., Matúš, K., \& Simon, W. (2016). Improved maximum strength, vertical jump and sprint performance after 8 weeks of jump squat training with individualized loads. Journal of Sports Science \& Medicine, 15(3), 492-500.

Maszczyk, A., Golas, A., Pietraszewski, R., Roczniok, A., Zajac, A, \& Stanula, A. (2014). Application of neural and regression models in sport results prediction. Procedia - Social and Behavioral Sciences, 117, $482-487$.

Maszczyk. A., Roczniok, R., Waśkiewicz, Z., Czuba, M., \& Mikołajec K. (2012). Application of regression and neural models to predict competitive swimming performance. Perceptual and Motor Skills, 114(2), 610-626.

Mathisen, G., Pettersen, A.A. (2015). Anthropometric factors related to sprint and agility performance in young male soccer players. Open Access Journal of Sports Medicine, 6, 337-342.

McCullagh, J. \& Whitfort, T. (2013). An investigation into the application of Artificial Neural Networks to the prediction of injuries in sport. World Academy of Science, Engineering and Technology International Journal of Sport and Health Sciences, 7(7), 356-360.

Mujika, I, Spencer, M, Santisteban, J, Goiriena, J.J., Bishop, D. (2009). Age-related differences in repeatedsprint ability in highly trained youth football players. Journal of Sports Sciences, 27 (14), 1581-1590.

Negra, Y., Chaabene, H., Hammami, M., Amara, S., Sammoud, S., Mkaouer, B., \& Hachana, Y. (2017). Agility in young athletes: Is it a different ability from speed and power? Journal of Strength and Conditioning Research, 31(3), 727-735.

Papaiakovou, G., Giannakos, A., Michailidis, C, Patikas, D., Bassa, E., Kalopisis, et al. (2009). The effect of chronological age and gender on the development of sprint performance during childhood and puberty. The Journal of Strength and Conditioning Research, 23, 2568-2573.

Rowland, T.W. (2005). Childrens exercise physiology. Human Kinetics, Champaign, IL

Scott, J.P. (1986). Critical periods in organizational process. In F. Falkner \& J.M. Tanner (Eds.), Human Growth. Vol. 1. Developmental Biology, Prenatal Growth, (pp. 181-196). New York, Plenum Press,

Shevade, S.S., Keerthi, C., \& Bhattacharyya, K.R.K., (1999). Murthy: Improvements to the SMO Algorithm for SVM Regression. IEEE Transactions on Neural Networks, 11, 1188-1193.

Silva, A.J., Costa, A.M., Oliveira, P. M., Reis, V.M., Saavedra, J., Perl, J., et al. (2007). The use of neural network technology to model swimming performance. Journal of Sports Science \& Medicine, 6(1), 117-125.

Smith, J.J., Eather, N., Morgan, P.J., Plotnikoff, R. C., Faigenbaum, A.D., \& Lubans, D. R. (2014). The health benefits of muscular fitness for children and adolescents: a systematic review and meta-analysis. Sports Medicine, 44(9), 1209-23.

Viru, A., Loko, J., Harro, M.,Volver, A.,Laaneots, L.,Viru, M. (1999). Critical periods in the development of performance capacity during childhood and adolescence. European Journal of Physical Education, 4,1, 75-119.

Williams, C.A., Oliver, J.L., \& Faulkner, J. (2011). Seasonal monitoring of sprint and jump performance in a soccer youth academy. International Journal of Sports Physiology and Performance, 6, 264-275.

Wong, P.L, Chamari, K, Dellal, A., \& Wisløff, U. (2009). Relationship between anthropometric and physiological characteristics inyouth soccer players. Journal of Strength and Conditioning Research, 23, 1204-1210.

Young, W. B., McDowell, M.H., \& Scarlett, B.J. (2001). Specificity of sprint and agility training methods. Journal of Strength and Conditioning Research, 15, 315-319.

Young, W., Hawken, M., L., \& MCdonald, L. (1996). Relationship between speed, agility and strength qualities in Australian Rules football. Strength \& Conditioning Coach, 4(4), 3-6. 


\section{REGRESIONI ALGORITMI U PROCENI UTICAJA MORFOLOŠKIH I MOTORIČKIH KARAKTERISTIKA NA SPRINT 60-METARA}

Cilj ovog rada je da se identifikuju relacije između morfoloških parametara $i$ motoričkih sposobnosti koje su važne za performansu sprinta kod dece od 8 do 16 godina, oba pola, podeljenih u četiri uzrastne grupe (U10, U12, U14, U16). Uzorak ispitanika činilo je 281 učenika koji su trenirali sprintersko trčanje u različitim atletskim klubovima. Set prediktora činilo je dvadeset i pet varijabli za procenu morfololoških karakteristika i motoričkih sposobnosti, a kriterijumska varijabla je bila sprint na 60m. Višestrukom korelacijom utvrđeno je da je veliki broj morfoloških karakteristika u statistički značajnoj pozitivnoj korelaciji sa sprintom, naročito longitudionalne varijable, dok su varijable potkožnih nabora pokazale slabu negativnu statičku značajnost $u$ odnosu na zadati kriterijum. $U$ domenu motoričkih testova najveći broj pozitivnih statistički značajnih korelacija ustanovljen je $u$ testovima ekslozivne snage gornjih $i$ donjih ekstremiteta, testu agilnosti i testovima horizontalnog $i$ vertikalnog skoka. Da bi ustanovili koja morfološka obeležja i koje motoričke veštine treba primeniti u treningu sprinta, testirali smo korišćene atribute pomoću algoritama za istraživanje podataka (LR, M5, KNN, SVM, MLP, RBF). Rezultati potvrđuju da se prediktori koje smo koristili mogu i dalje primeniti sa visokom pouzdanošću u proceni sprinterske performanse, a i u monitoringu trenažnog procesa u cilju profilisanja boljih sprinterskih dostignuća.

Ključne reči: mladi sportisti, sprint, morfološke karakteristike, motoričke sposobnosti, algoritmi regresije 